\title{
Heart sarcoma and invasion of the mitral valve: Case report
}

\author{
Lakehal Redha ${ }^{1}$, Aimer Farid ${ }^{1}$, Bouharagua Rabeh ${ }^{1}$, Cherif Samiha ${ }^{1}$, Massikh Nadjet ${ }^{1}$, \\ Aziza Baya $^{1}$, Bendjaballah Soumaya ${ }^{1}$, Boukharoucha Radouane ${ }^{1}$, Brahami Abdelmallek ${ }^{1}$
}

${ }^{1)}$ Department of heart surgery, EHS Erriadh, Constantine, Algeria

\begin{abstract}
Primary cardiac sarcoma is a malignant and rare type of tumor that occurs in the heart. About $25 \%$ of primary cardiac tumors are malignant, and $95 \%$ of these are sarcomas. The most common cardiac sarcoma is the angiosarcoma (about $37 \%)$, while others include undifferentiated sarcoma (24\%), malignant fibrous histiocytoma (MFH) $(11 \%-24 \%)$, leiomyosarcoma ( $8 \%-9 \%)$, and osteosarcoma (3\%-9\%). The diagnosis of these tumors is made by imaging techniques and pathological study. This new case report is an opportunity for us to make a reminder of this little-known entity among cardiologists and heart surgeon.
\end{abstract}

Keywords: Cardiac sarcoma, mitral valve, malignant fibrous histiocytoma.

Redha L., Farid A., Rabeh B., at all. Heart sarcoma and invasion of the mitral valve: Case report. EJCM 2015; 03 (2): 35-39. DOI: 10.15511/ejcm.15.00235. 


\section{Introduction}

Primary cardiac sarcoma is a malignant and rare type of tumor that occurs in the heart. About $25 \%$ of primary cardiac tumors are malignant, and $95 \%$ of these are sarcomas. The most common cardiac sarcoma is the angiosarcoma (about 37\%), while others include undifferentiated sarcoma (24\%), malignant fibrous histiocytoma (MFH) (11\%-24\%), leiomyosarcoma (8\%-9\%), and osteosarcoma (3\%-9\%). Less encountered primary tumors of the heart include rhabdomyosarcoma, liposarcoma, fibrosarcoma, synovial sarcoma, and hemangiopericytoma, with the least reported cardiac tumors being the intimal (spindle cell) sarcomas.

The mean age of presentation is around 40 years with no sex predilection. Patients present after variable periods of symptoms which are often non-specific, ranging from few weeks to several months and almost

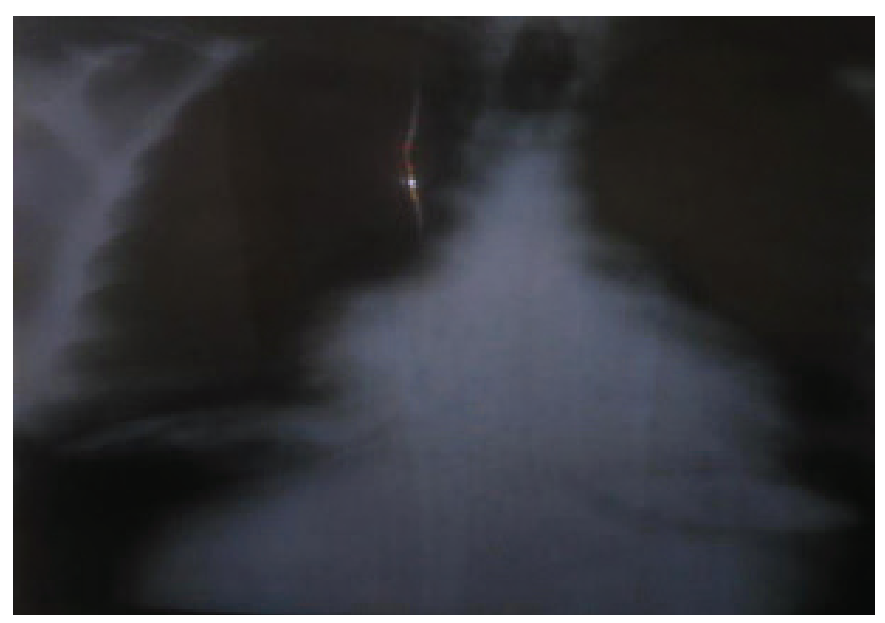

Figure 1. Chest $X$ ray

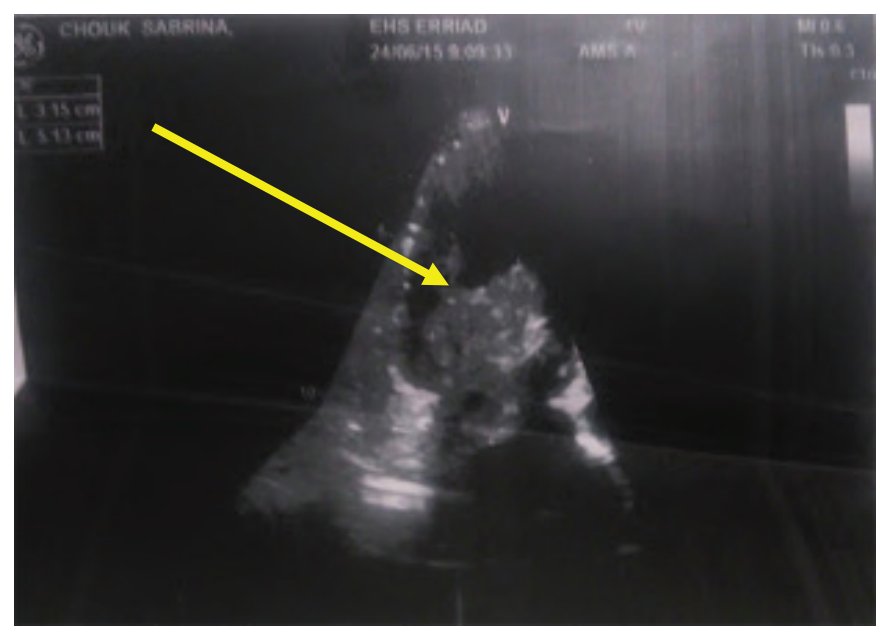

Figure 3. Echocardiography showing a tumor in the posterior wall of left atrium all are symptomatic at presentation. The diagnosis of these tumors is made by imaging techniques and pathological study.

\section{Objective}

This new case report is an opportunity for us to make a reminder of this little-known entity among cardiologists and heart surgeon.

\section{Methods}

We report the case of 39 years old female presented with 2 months history of acute onset dyspnea, lethargy, weight loss, night sweats, and malaise. Clinical examination, blood tests and chest $\mathrm{x}$ ray were unremarkable.

\section{Chest $X$ ray:}

Echocardiography: Showed:

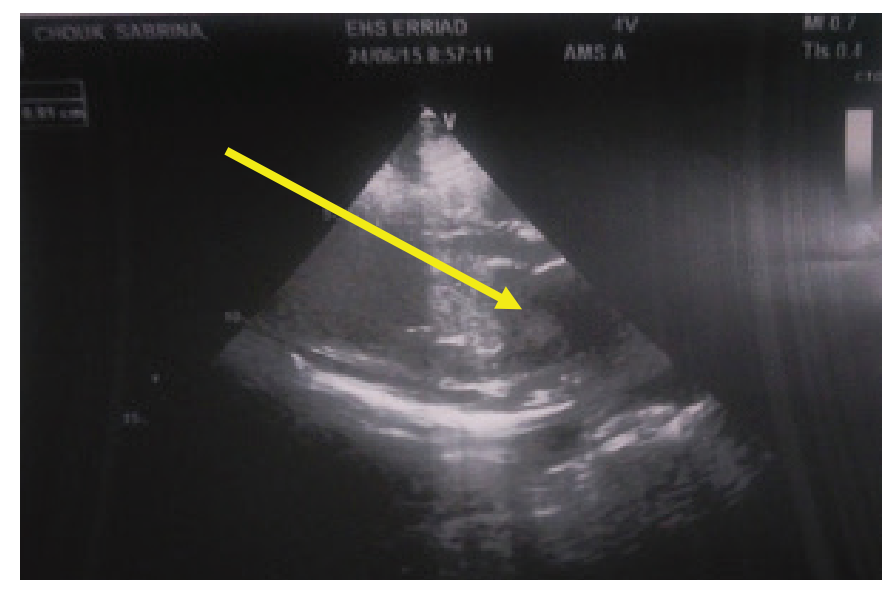

Figure 2. Echocardiography showing a tumor in the posterior wall of left atrium

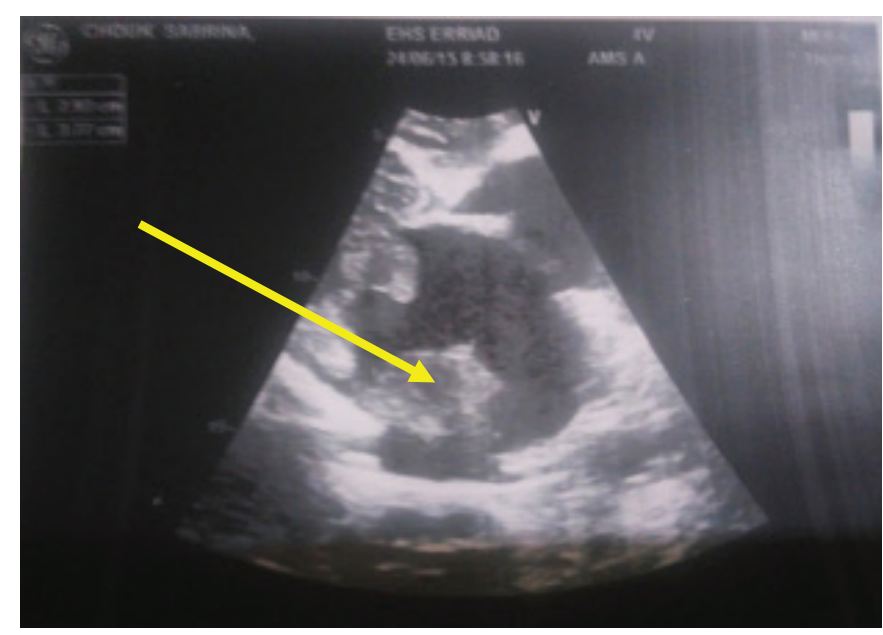

Figure 4. Echocardiography showing a tumor in the posterior wall of left atrium 
A large $(3,8 \times 2,4 \mathrm{~cm}$ in diameter) echogenic and multi lobular mass in the left atrium with moderate mitral regurgitation. It is observed that the mass has invaded the left atrial wall and mitral valve.

Transesophageal echocardiogram (TEE) and computed tomographic (CT) scan: Don't realize.

\section{Surgery}

She was referred for surgical assessment after the findings of left atrial mass. The patient was opered under cardiopulmonary bypass. The approach was sternotomy.

The per operative exploration: Infiltrating the left atrial wall and mitral valve. A curative resection was

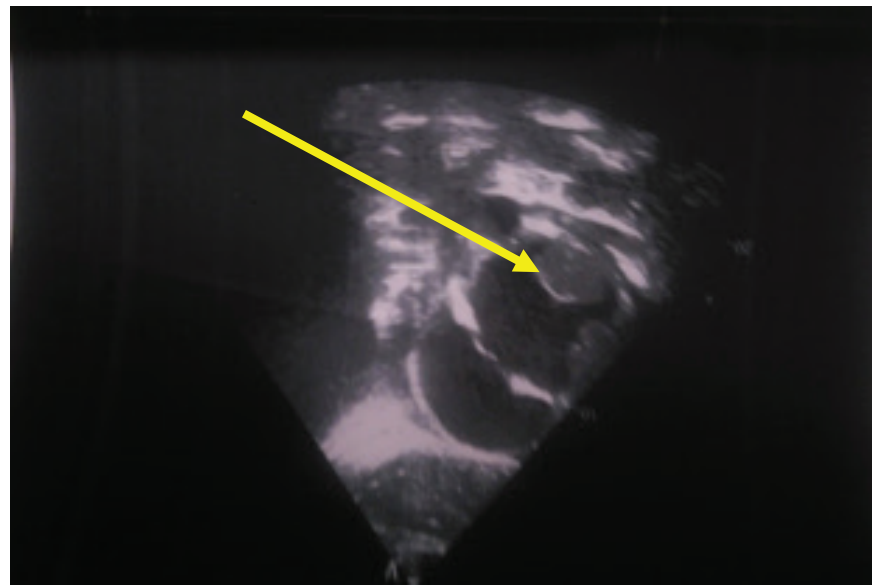

Figure 5. Echocardiography showing a tumor in the posterior wall of left atrium

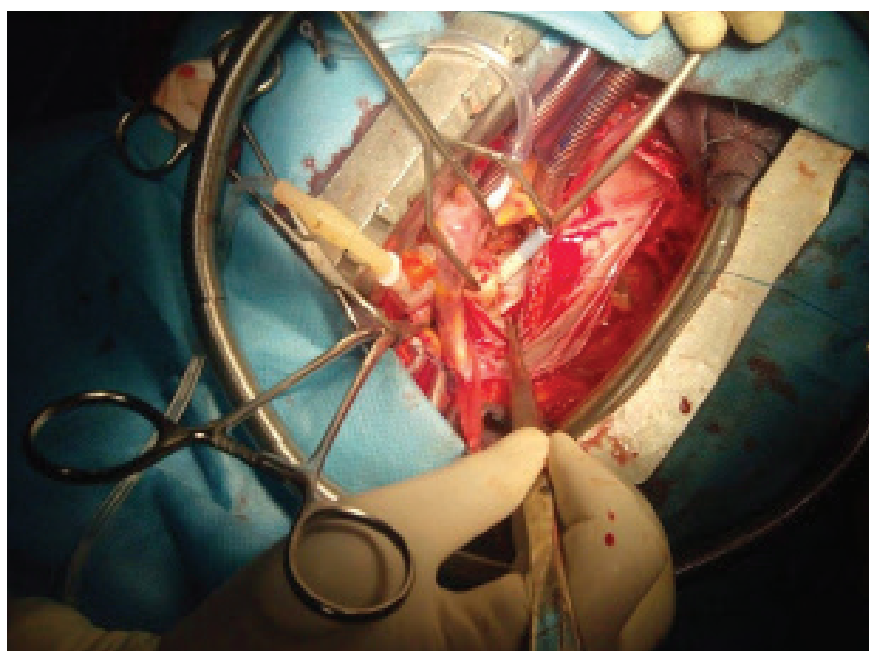

Figure 7. Operative view showing a heart tumor deemed impossible. At surgery a large tumor was found arising from the left atrial side. It was solid in consistency and had a wide base. It was partly extending to mitral valve.

The guesture was resected of tumor as completely as possible and mitral valve replacement under CPB.

Macroscopic examination of the cardiac specimen revealed polypoid atrial masses weighing 30.4 grams with a side to side dimension of $4.3 \mathrm{~cm}$, length of up to $4.5 \mathrm{~cm}$, and a thickness of up to $2.9 \mathrm{~cm}$ from the atrial endocardium. The mass involved the atrial wall posteriorly and the entire posterior mitral leaflet, except for its free margin. The most protuberant part of the mass was
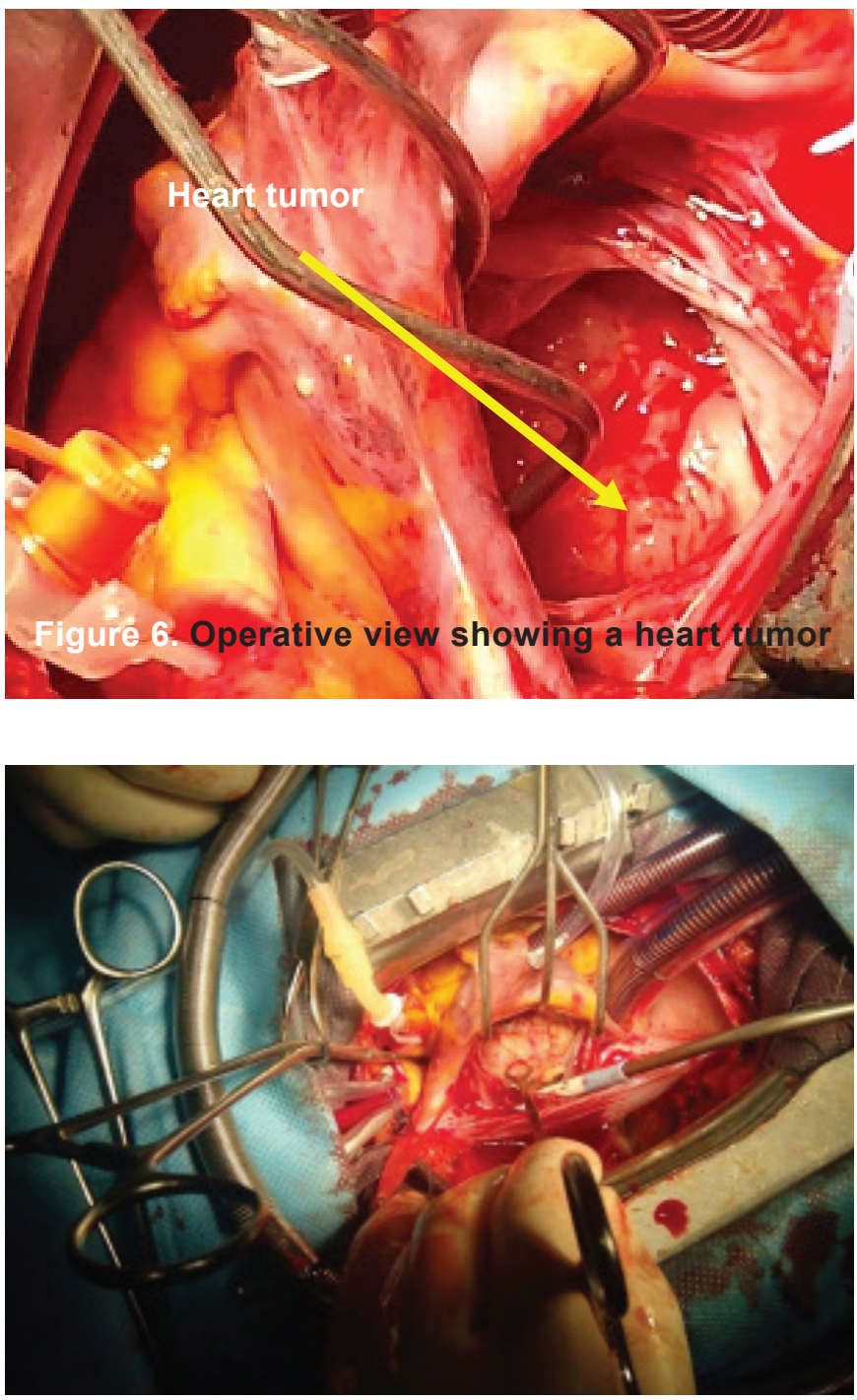

Figure 8. Operative view showing a heart tumor 
considerably softer in consistency and deeper yellow in color with small darker areas.

\section{Results}

Duration of CPB: $123 \mathrm{mn}$.

Aortic clamping: $108 \mathrm{mn}$.

The immediate postoperative course was simple.

Stay in intensive care unit: 48 hours.

Intubation procedure: 14 hours.

Post operative stay: 07days.

Histopathologic examination of the left atrial mass showed an heart sarcoma. She underwent chemotherapy.

\section{Comments}

Sarcomas of the left atrium are extremely rare primary cardiac tumors. Histologically, heart sarcomas are usually poorly differentiated mesenchymal malignant tumors of fibroblastic or myofibroblastic differentiation, consisting of atypical spindle cells with variable degrees of atypia, mitotic activity, necrosis, and nuclear polymorphism. The tumor may exhibit large myxoid areas and or epithelioid appearance of tumor cells. Tumor cells may resemble leiomyosarcoma and rarely exhibit

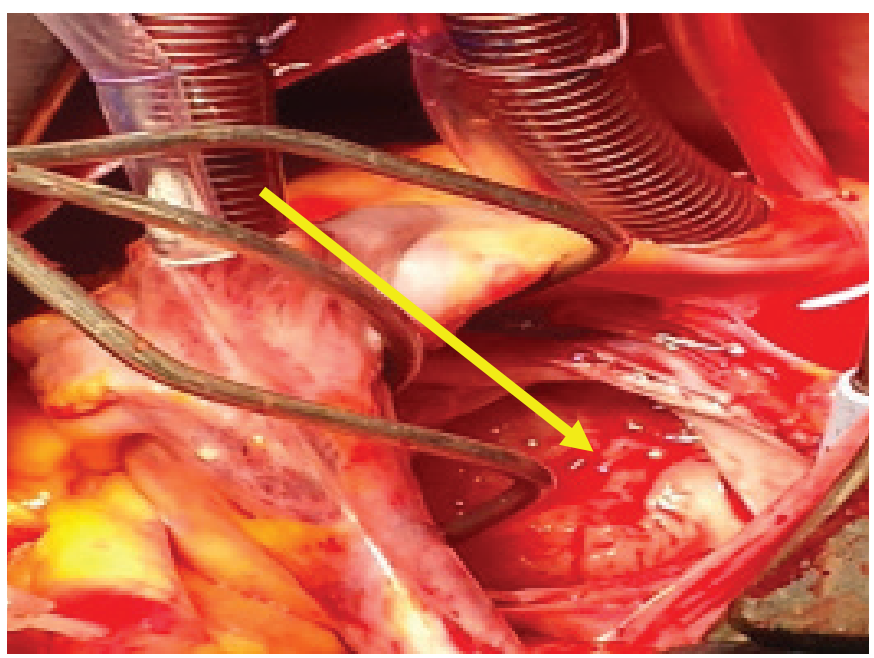

Figure 9. Operative view showing a heart tumor areas of rhabdomyomatous, angiosarcomatous.

The prognosis of cardiac primary sarcomas is generally poor. These tumors are highly aggressive with the mean survival being 3 months to 1 year. Cardiac tumors can cause significant morbidity and mortality. The effects of a cardiac tumor depend on its anatomical location in the heart, size, invasiveness, friability, and the rate of growth. The most important factor affecting the prognosis of these tumors is the anatomical location in the heart (intracavitary versus intra/extramyocardial growth).

Although aggressive surgery can offer dramatic palliation of symptoms caused by valvular and/or vascular obstruction, local recurrence and metastasis occur frequently and early, usually within 1 year. Chemotherapy and radiation therapy have limited benefit.

\section{Conclusion}

Heart surgery is the treatment of choice for sarcoma. Cardiac sarcomas generally lead to death within 2 years of diagnosis, due to rapid infiltration of the myocardium of the heart and obstruction of the normal flow of blood within the heart.

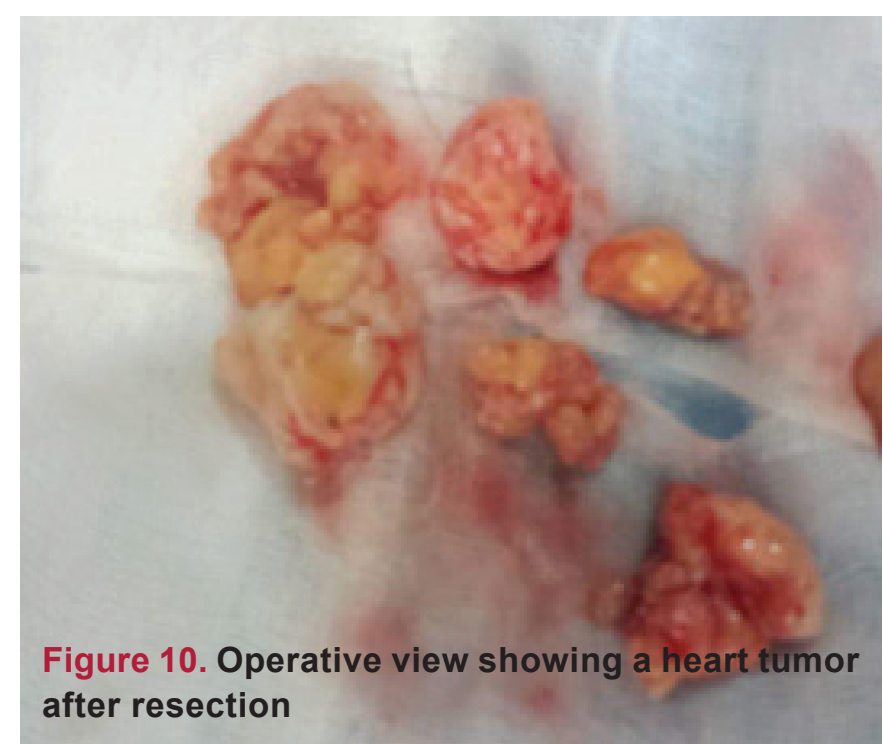




\section{References}

1. Straus R, Merliss R: Primary tumours of heart. Arch Pathol 1945, 39:74.

2. Reardon, Smythe : Cardiac neoplasms. In Cardiac surgery in the adult. 2nd edition. Edited by: Edmunds LH Jr. New york, NY:McGrawHill; 2003:1373-1400.

3. Mc Allister HA, Fenoglio JJ: Tumours of cardiovascular system in: Atlas of tumour pathology, series 2. Washington, DC: Armed Forces Institute of Pathology; 1978.

4. J. Butany, V. Nair, A. Naseemuddin, G. M. Nair, C. Catton, and T. Yau, "Cardiac tumours: diagnosis and management," The Lancet Oncology, vol. 6, no. 4, pp. 219-228, 2005.

5. K. A. Ekmektzoglou, G. F. Samelis, and T. Xanthos, "Heart and tumors: location, metastasis, clinical manifestations, diagnostic approaches and therapeutic considerations," Journal of Cardiovascular Medicine, vol. 9, no. 8, pp. 769-777, 2008.

6. K. Reynen, "Frequency of primary tumors of the heart," American Journal of Cardiology, vol. 77, no. 1, p. 107, 1996.

7. Z. Li, T. Hsieh, and A. Salehi, "Recurrent cardiac intimal (Spindle cell) sarcoma of the left atrium,"Journal of Cardiothoracic and Vascular Anesthesia, vol. 27, no. 1, pp. 103-107, 2013.

8. G. J. Cho, H. J. Kim, and J. S. Kang, "Primary cardiac sarcoma in pregnancy: a case report,” Journal of Korean Medical Science, vol. 21, no. 5, pp. 940-943, 2006
9. A. Modi, A. Lipnevicius, N. Moorjani, and M. Haw, "Prolonged survival with left atrial spindle cell sarcoma," Interactive Cardiovascular and Thoracic Surgery, vol. 8, no. 6, pp. 703-704, 2009.

10. M. J. Perchinsky, S. V. Lichtenstein, and G. F. Tyers, "Primary cardiac tumors: forty years' experience with 71 patients," Cancer, vol. 79, no. 9 pp. 1809-1815, 1997.

11. H. P. Goldberg, F. Glenn, C. T. Dotter, and I. Steinberg, "Myxoma of the left atrium; diagnosis made during life with operative and post-mortem findings," Circulation, vol. 6, no. 5, pp. 762-767, 1952.

12. W. R. Chitwood Jr., "Clarence Crafoord and the first successful resection of a cardiac myxoma," Annals of Thoracic Surgery, vol. 54, no. 5, pp. 997-998, 1992.

13. B. Bode-Lesniewska, J. Zhao, E. J. M. Speel et al., "Gains of 12q13-14 and overexpression of mdm2 are frequent findings in intimal sarcomas of the pulmonary artery," Virchows Archiv, vol. 438, no. 1, pp. 57-65, 2001.

14. A. Gaumann, D. S. Tews, E. Mayer et al., "Expression of apoptosisrelated proteins, $\mathrm{p} 53$, and DNA fragmentation in sarcomas of the pulmonary artery," Cancer, vol. 92, no. 5, pp. 1237-1244, 2001.

15. M. H. Seelig, P. J. Klingler, W. A. Oldenburg, and J. L. Blackshear, “Angiosarcoma of the aorta: report of a case and review of the literature," Journal of Vascular Surgery, vol. 28, no. 4, pp. 732-737, 1998.

Received: 17/03/2015

Accepted: 27/08/2015

Published: 15/10/2015

Disclosure and conflicts of interest:

The authors declare no conflict of interest.

\section{Corresponding author:}

Dr. Redha Lakehal

Mail: lakehal.redha@gmail.com 